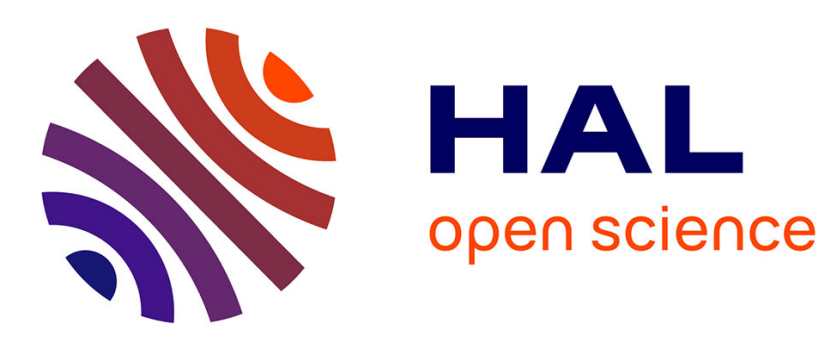

\title{
Reduced adsorption of caesium on clay minerals caused by various humic substances
}

\author{
Camille Dumat, S. Staunton
}

\section{To cite this version:}

Camille Dumat, S. Staunton. Reduced adsorption of caesium on clay minerals caused by various humic substances. Journal of Environmental Radioactivity, 1999, vol. 46, pp.187-200. 10.1016/S0265931X(98)00125-8 . hal-00974905

\section{HAL Id: hal-00974905 https://hal.science/hal-00974905}

Submitted on 7 Apr 2014

HAL is a multi-disciplinary open access archive for the deposit and dissemination of scientific research documents, whether they are published or not. The documents may come from teaching and research institutions in France or abroad, or from public or private research centers.
L'archive ouverte pluridisciplinaire HAL, est destinée au dépôt et à la diffusion de documents scientifiques de niveau recherche, publiés ou non, émanant des établissements d'enseignement et de recherche français ou étrangers, des laboratoires publics ou privés. 


\title{
Reduced adsorption of caesium on clay minerals caused by various humic substances
}

\author{
C. Dumat, S. Staunton* \\ U.F.R. de Science du Sol, I.N.R.A., 2 place Viala, 34060 Montpellier Cedex, France
}

\begin{abstract}
The effect of the addition of various humic substances on the adsorption of caesium on two mineral clays has been studied. All measurements were carried out in dilute suspension under controlled conditions of temperature and ionic strength. Only a small proportion of the humic substance was adsorbed on the clays $(<10 \%)$. In general, the affinity of the clay-humic complexes for caesium was less than that of the bare clay. The decrease was greater for illite than for montmorillonite, and greatest at trace concentrations of caesium and increased with increasing concentration of each humic substance. However, no correlation was found between the amount of humic substance adsorbed and the decrease in Cs adsorption when all complexes were considered. Neither size nor the origin of the humic substances could explain the extent of the adsorption decrease. Since neither steric hindrance nor decrease in the number of adsorption sites was the driving force behind this phenomenon, it is hypothesized that the affinity of the clay surface is modified by the organic macromolecules. The highly selective frayed edge sites of illite are particularly sensitive to the adsorption of polyanions because of their proximity to anion adsorption sites. The observed decrease in Cs adsorption may contribute to the unexpectedly high bioavailability of Cs in organic soils. (C) 1999 Elsevier Science Ltd. All rights reserved.
\end{abstract}

\section{Introduction}

The radioisotopes of caesium, ${ }^{137} \mathrm{Cs}$ and ${ }^{134} \mathrm{Cs}$, with half-lives of 30.4 and 2.1 years, respectively, have been introduced into the environment by various events, notably fallout from the atmospheric weapons testing in the 1950s and 1960s and accidents such as the one at the Chernobyl nuclear power plant in 1986. The environmental and radioecological problems posed by caesium contamination of soils are long term, and

\footnotetext{
*Corresponding author: Tel.: 003349961 2331; fax: 003346763 2614; e-mail: staunton@ensam.inra.fr
} 
accurate prediction is required. Adsorption of caesium on soil constituents is one of the factors which determines the availability of radiocaesium to biological systems. It is well known that caesium is strongly adsorbed on clay minerals (Sawhney, 1972; Maes \& Cremers, 1986; Cornell, 1993). This adsorption is highly specific, particularly on illitic materials which are thought to contain a small proportion of sites, frayed edge sites (FES), which have a very strong affinity for caesium (Brouwer, Baeyens, Maes \& Cremers, 1983). In contrast, the adsorption of caesium on organic matter is non-specific, and depends on the cation exchange capacity (CEC) of the organic matter and the relative proportions of caesium and other cations present. Indeed other cations may be preferentially associated with organic matter in soils and sediments. The formation of complexes between Cs and organic ligands is negligible.

Nevertheless, some observations on the fate of radiocaesium in soils lead us to suspect that organic matter does play some role in the extent and strength of adsorption. It is widely observed that radiocaesium is more easily available to biological systems in soils with high organic matter contents (Barber, 1964; van Bergeijk, Noordijk, Lembrechts \& Frissel, 1992), and therefore, by implication, less strongly adsorbed. A simple explanation for this would be that organic soils and peats do not contain sufficient quantities of clay materials, particularly illites, to effectively immobilise caesium. However, recent studies have shown that even peats contain trace amounts of illite (Hird, Rimmer \& Livens, 1995), which should be more than sufficient to adsorb the trace amount of caesium present even in the most highly contaminated soils. For example, an OECD report (OCDE, 1987) gives the greatest recorded contamination of ${ }^{137} \mathrm{Cs}$ due to the accident at Chernobyl in a member country as $190 \mathrm{kBq} \mathrm{m}^{-2}$ in Sweden. As little as $1 \mathrm{mg}$ illite $\mathrm{kg}^{-1}$ soil (assuming the cation exchange capacity of illite to be $0.1 \mathrm{~mol}_{\mathrm{c}} \mathrm{kg}^{-1}$ and the proportion of highly selective sites to be $1 \%$ ) would have sufficient capacity to adsorb this amount of Cs. It is possible that the presence of organic matter reduces the affinity of clay minerals for Cs. Other possible explanations of the ongoing bioavailability of Cs in highly organic upland soils depend on plant physiology, and are beyond the scope of this study.

A small number of studies have suggested that the presence of humic substances does decrease the adsorption of Cs (Bunzl \& Schultz, 1985; Maguire, Pulford, Cook \& Mackenzie, 1992; Hsu \& Chang, 1995). We consider that the generality of this effect should be tested. In a previous study, we have shown that the removal of organic matter from a soil clay increases its affinity for caesium (Dumat, Cheshire, Fraser, Shand \& Staunton, 1997). For the present study, the effect of the addition of humic acid and fulvic acid from three different origins to two reference clays, a montmorillonite and an illite is studied. We have chosen to investigate humic substances because they constitute a large proportion of soil organic matter. The amount of adsorbed humic substance in the complexes studied is far less than the organic matter content of the organic upland soils in which Cs bioavailability is a particular problem. However, if soil organic matter modifies the affinity of minerals for Cs, only the small proportion directly associated with clay minerals could play a role.

The effect was studied at two initial caesium concentrations at varying ratios of clay to humic substance. A short exchange period was used $(2 \mathrm{~h})$ to ensure that only true ion exchan ${ }^{J}$ ge was measured, with no interference from either long term weathering 
effects of the humic substances on the clays or the slow adsorption of Cs characteristic of illites. The clays were chosen for their differing affinity for caesium, resulting from different adsorption mechanisms. Similarly, a comparison of the phenomenon at two concentrations of caesium, when different adsorption sites may dominate adsorption, allows us to clarify the origin of the observed effect. At trace additions of Cs the adsorption on illites is dominated by highly selective sites which account for a small proportion of the cation exchange capacity. At larger Cs concentrations the affinity may be determined by the regular exchange sites, which are external planar sites and are very similar to those of montmorillonite. This point will be considered in greater detail in the Discussion. Even the trace Cs concentration used in this study is in excess of levels found in contaminated soil, however, since the extent of the decrease in Cs adsorption increases with decreasing Cs loading, the effect of organic matter should be at least as great in situ.

\section{Materials and methods}

Two reference clays were investigated, a Wyoming montmorillonite (M) and an illite from Le Puy (I), France. Their principal characteristics are given in Table 1. The clay-sized fraction $(<2 \mu \mathrm{m})$ was extracted from both minerals by sedimentation, saturated in $\mathrm{Ca}$ by repeated suspension in $1 \mathrm{M} \mathrm{CaCl}_{2}$ and dialysed until salt free and the concentration adjusted to $20 \mathrm{~g} \mathrm{dm}^{-3}$. The humic substances (HS) were isolated from three different sources; Suwannee River, Peat and a Nordic Aquatic system. They were obtained from the International Humic Substance Society (IHSS) and used without further purification. The composition of the humic substances is presented in Table 2. After dissolving the fulvic acids in water, and the humic acids in $0.1 \mathrm{M}$ $\mathrm{NaOH}$, the solutions were then adjusted to $\mathrm{pH} 7$ with $\mathrm{NaOH}$ or $\mathrm{HCl} .{ }^{137} \mathrm{Cs}$ was obtained from Amersham International as an aqueous solution containing trace amounts of stable carrier Cs.

The Cs adsorption was carried out as follows. Triplicate suspensions of clay were prepared in polypropylene tubes by mixing appropriate volumes of clay suspension and solutions of $\mathrm{Cs}$, humic substance and $\mathrm{CaCl}_{2}$ used as a background electrolyte. The concentrations of the various components was as follows: $\mathrm{CaCl}_{2} 3.33 \mathrm{mM}$ (ionic strength $10^{-2} \mathrm{M}$; clay $1 \mathrm{~g} \mathrm{dm}^{-3}$; humic substance $0,0.05,0.1$ or $0.25 \mathrm{~g} \mathrm{dm}^{-3} ; \mathrm{CsCl} 0$ or $10^{-5} \mathrm{M} ;{ }^{137} \mathrm{Cs} 1$ or $2 \mathrm{MBq} \mathrm{dm}{ }^{-3}$, equivalent to 6.7 and $13.4 \mathrm{nM} \mathrm{Cs}$ (the higher ${ }^{137} \mathrm{Cs}$

Table 1

Principal characteristics of the minerals studied

\begin{tabular}{lll}
\hline Clay & Illite & Montmorillonite \\
\hline $\mathrm{CEC} / \mathrm{mol}_{\mathrm{c}} \mathrm{kg}^{-1}$ & 0.3 & 0.94 \\
Specific surface area $/ \mathrm{m}^{2} \mathrm{~g}^{-1}$ & 90 & 800 \\
Major minerals & Illite & Montmorillonite \\
Trace minerals & Feldspar and kaolinite & Quartz \\
\hline
\end{tabular}


Table 2

Composition of the humic substances investigated, \% by weight (analyses supplied by the IHSS)

\begin{tabular}{|c|c|c|c|c|c|c|c|}
\hline Sample & $\mathrm{C}$ & $\mathrm{H}$ & $\mathrm{O}$ & $\mathrm{N}$ & $\mathrm{S}$ & $\mathrm{P}$ & Ash \\
\hline FA (river) & 53.04 & 4.36 & 43.91 & 0.75 & 0.46 & $<0.01$ & 0.98 \\
\hline FA (peat) & 52.12 & 3.23 & 43.93 & 2.43 & 0.53 & 0.01 & 1.58 \\
\hline FA (aquatic) & 52.31 & 3.98 & 45.12 & 0.68 & 0.46 & $<0.01$ & 0.45 \\
\hline HA (river) & 52.89 & 4.14 & 43.40 & 1.17 & 0.58 & $<0.01$ & 3.46 \\
\hline HA (peat) & 56.84 & 3.60 & 36.62 & 3.74 & 0.70 & 0.03 & 1.72 \\
\hline HA (aquatic) & 53.33 & 3.97 & 43.09 & 1.16 & 0.58 & 0.01 & 0.31 \\
\hline
\end{tabular}

level for the systems containing illite which has a greater Cs adsorption capacity). The final $\mathrm{pH}$ of the suspensions was $7 \pm 0.3$. The sodium present in the solutions of humic substance led to a Na concentration in the suspension of about $10^{-4} \mathrm{M}$. The presence of this amount of sodium did not change the Cs adsorption properties of the clays. These suspensions were shaken in a reciprocal shaker for $2 \mathrm{~h}$ at $20^{\circ} \mathrm{C}$ then centrifuged at $19000 \mathrm{~g}$ for $30 \mathrm{~min}$. Preliminary experiments have shown that these conditions are adequate to ensure complete separation of the aqueous and solid phases. Triplicate aliquots of the supernatant solution were taken, added to scintillation liquid and the $\beta$ radiation was measured in a Beckman LS 5801 counter.

The distribution coefficient, $K_{\mathrm{d}}$ is defined as follows,

$$
K_{\mathrm{d}}=x_{\mathrm{Cs}} /[\mathrm{Cs}]
$$

where $x_{\mathrm{Cs}}$ is the amount of Cs adsorbed on unit mass of clay $\left(\mathrm{mol} \mathrm{kg}^{-1}\right)$ and $[\mathrm{Cs}](\mathrm{M})$ is the final concentration in solution. The value of $K_{\mathrm{d}}$ was calculated from the depletion of ${ }^{137} \mathrm{Cs}$ from solution, by comparison with a blank solution to which no clay had been added.

A small proportion of humic substance is adsorbed, it is therefore not possible to determine the amount adsorbed by measuring the loss from solution. The amount of humic substance adsorbed on the clays was therefore interpolated from the $\mathrm{C}$ content clay-humic substance complexes obtained as follows. Suspensions containing $50 \mathrm{~g}$ clay and $5 \mathrm{~g}$ humic substance were shaken overnight then centrifuged at $19000 \mathrm{~g}$ for $30 \mathrm{~min}$. The supernatant solution was decanted off, and the remaining solution removed by gently rinsing with water. The resulting plug was freeze dried and the $\mathrm{C}$ content measured using a Carlo Erba 1500. The amount of humic substance adsorbed was calculated from the known $\mathrm{C}$ content of the humic substance, supplied by the IHSS, and the $\mathrm{C}$ content of the bare clay obtained by the same method. The results of this analysis are given in Table 3. Table 4 gives the calculated values of $x_{\mathrm{HS}} /[\mathrm{HS}]$ and $x_{\mathrm{HS}}$ for each clay + humic substance complex where $x_{\mathrm{HS}}$ is the amount of humic substance adsorbed per unit mass of clay and [HS] the final solution concentration. The adsorption isotherm of humic substances on clay is assumed to be linear (Theng and Scharpenseel, 1975). This assumption was confirmed by preliminary experiments with illite and a different fulvic acid and so these values were used to 
Table 3

Carbon content of bare clays and clay + humic substance complexes

\begin{tabular}{lc}
\hline Sample & $x_{\mathrm{C}}: \mathrm{g}(\mathrm{C}) \mathrm{kg}^{-1}$ (solid) \\
\hline Illite (I) & 1.4 \\
Montmorillonite (M) & 2.2 \\
I + FA (river) & 36.4 \\
I + FA (peat) & 42.6 \\
I + FA (aquatic) & 43.6 \\
I + HA (river) & 46.0 \\
I + HA (peat) & 40.5 \\
I + HA (aquatic) & 45.2 \\
M + FA (river) & 16.7 \\
M + FA (peat) & 16.1 \\
M + FA (aquatic) & 17.4 \\
M + HA (river) & 20.2 \\
M + HA (peat) & 32.6 \\
M + HA (aquatic) & 19.8 \\
\hline
\end{tabular}

Table 4

Calculated value of $x_{\mathrm{HS}} /[\mathrm{HS}]$ and $x_{\mathrm{HS}}$ for each clay + humic substance complex

\begin{tabular}{|c|c|c|c|c|}
\hline \multirow{2}{*}{$\begin{array}{l}\text { Humic } \\
\text { substance }\end{array}$} & \multicolumn{2}{|l|}{ Illite } & \multicolumn{2}{|c|}{ Montmorillonite } \\
\hline & $\begin{array}{l}x_{\mathrm{HS}} /[\mathrm{HS}] \\
\left(\mathrm{dm}^{3} \mathrm{~kg}^{-1}\right)\end{array}$ & $\begin{array}{l}x_{\mathrm{HS}} \\
\left(\mathrm{g} \mathrm{kg}^{-1}\right)\end{array}$ & $\begin{array}{l}x_{\mathrm{HS}} /[\mathrm{HS}] \\
\left(\mathrm{dm}^{3} \mathrm{~kg}^{-1}\right)\end{array}$ & $\begin{array}{l}x_{\mathrm{HS}} \\
\left(\mathrm{g} \mathrm{kg}^{-1}\right)\end{array}$ \\
\hline \multicolumn{5}{|l|}{ Fulvic Acid } \\
\hline River & 0.049 & 71 & 0.008 & 28 \\
\hline Peat & 0.124 & 86 & 0.008 & 28 \\
\hline Aquatic & 0.147 & 88 & 0.009 & 30 \\
\hline \multicolumn{5}{|l|}{ Humic Acid } \\
\hline River & 0.242 & 92 & 0.011 & 35 \\
\hline Peat & 0.057 & 74 & 0.026 & 57 \\
\hline Aquatic & 0.175 & 90 & 0.010 & 34 \\
\hline
\end{tabular}

calculate the amount of each humic substance adsorbed when the initial solution concentration was $0.25 \mathrm{~g} \mathrm{dm}^{-3}$, which is used in Figs. 4 and 5 .

\section{Results}

Fig. 1 shows the effect of increasing amounts of each of the humic substances (HS) on the $K_{\mathrm{d}}$ value of illite with two initial Cs concentrations in solution. Fig. 2 gives the equivalent data obtained with montmorillonite. The standard deviation of the 

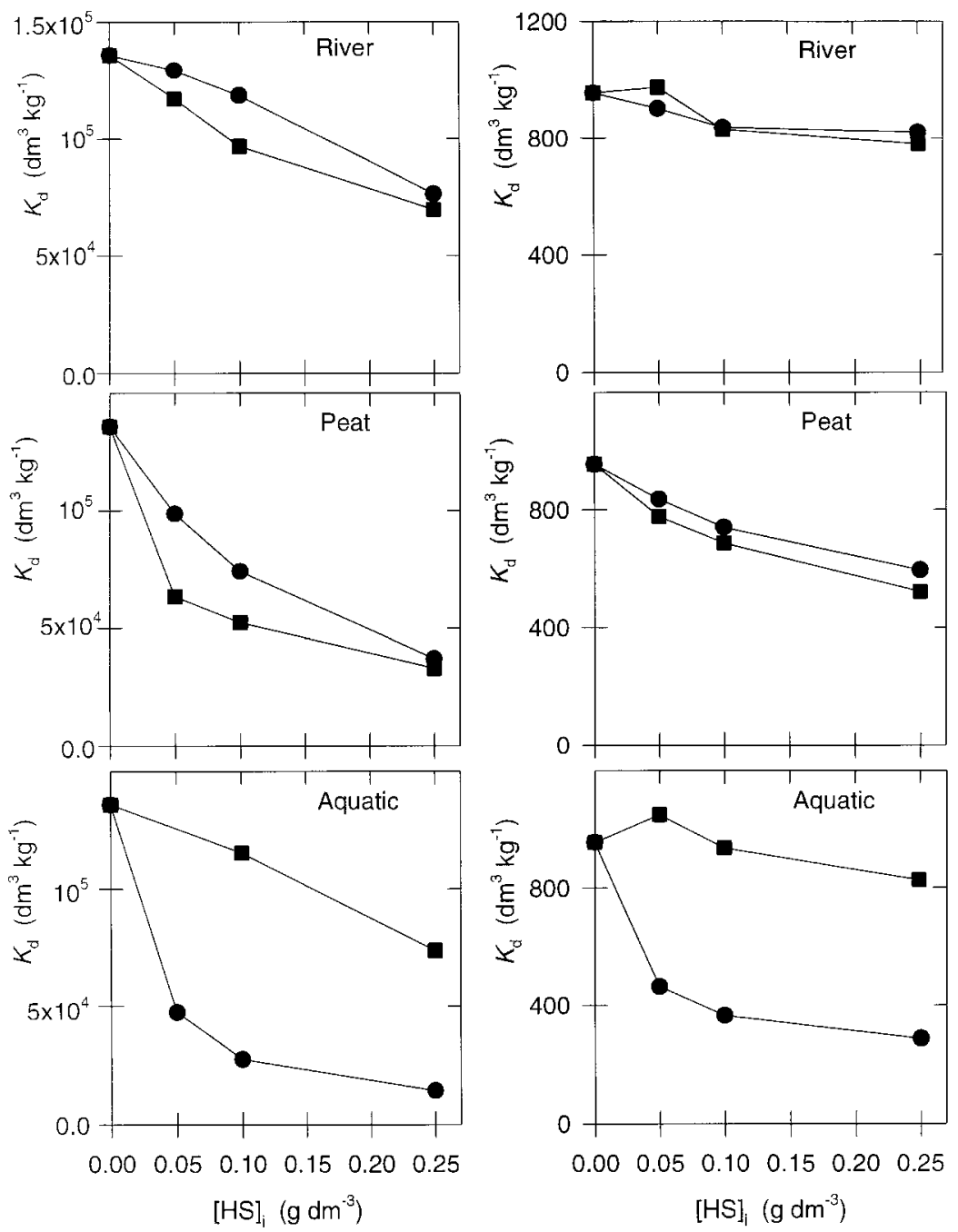

Fig. 1. Value of the distribution coefficient, $K_{\mathrm{d}}$, on illite as a function of initial concentration of humic substance in solution. Two initial Cs concentrations in solution were studied; $13.4 \mathrm{nM}$ or trace (left column) and $10 \mu \mathrm{M}$ (right column) for the fulvic and humic acids of Suwannee River, Peat and Nordic Aquatic system (from top to bottom). (ם) Fulvic acid; (@) Humic acid.

$K_{\mathrm{d}}$ values was about $5 \%$ and never exceeded $8 \%$. The $K_{\mathrm{d}}$ values for the bare clays illustrate the well-known fact that there is greater adsorption on illite than on montmorillonite and that adsorption is highly concentration dependent, as indicated by the smaller value of $K_{\mathrm{d}}$ at the higher Cs concentration. The concentration dependence is more marked for illite than for montmorillonite. The addition of humic substance leads in general to a decrease in the value of $K_{\mathrm{d}}$, with adsorption being less 

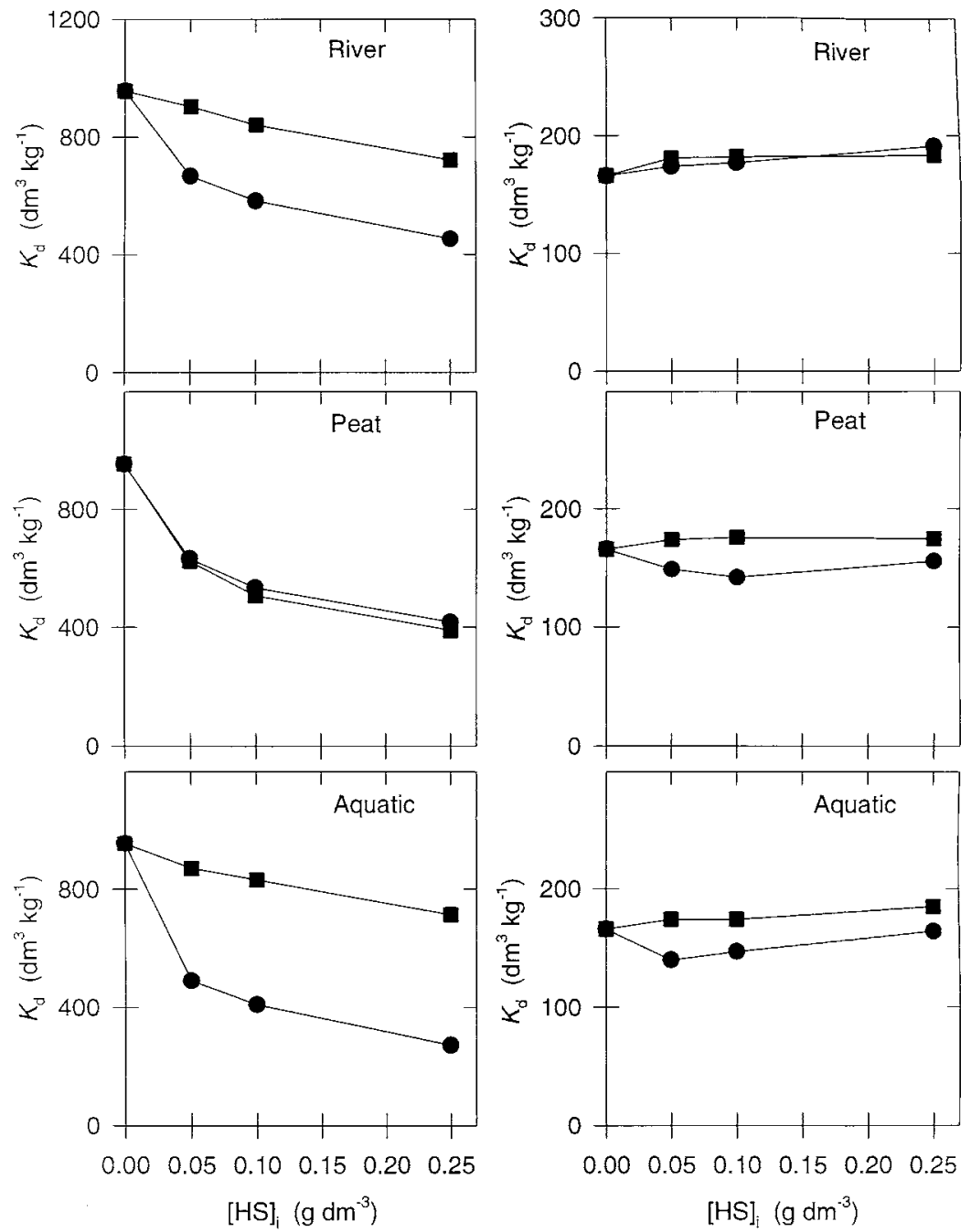

Fig. 2. Value of the distribution coefficient, $K_{\mathrm{d}}$, on montmorillonite as a function of initial concentration of humic substance in solution. Two initial Cs concentrations in solution were studied; $6.7 \mathrm{nM}$ or trace (left column) and $10 \mu \mathrm{M}$ (right column) for the fulvic and humic acids of Suwannee River, Peat and Nordic Aquatic system (from top to bottom). (ロ) Fulvic acid; (@) Humic acid.

affected in the case of montmorillonite than illite. A more marked effect at trace levels of Cs than at the higher initial Cs concentration is observed. There is no significant decrease in $K_{\mathrm{d}}$ with HS addition for montmorillonite when the initial Cs concentration is $10 \mu \mathrm{M}$.

Fig. 3 resumes the effect of the highest addition of humic substance on (a) illite and (b) montmorillonite for the two initial Cs concentrations. The value of $K_{\mathrm{d}}$ relative to that on the bare clay, denoted by ${ }^{*} K_{\mathrm{d}}$, has been calculated for each clay + humic 

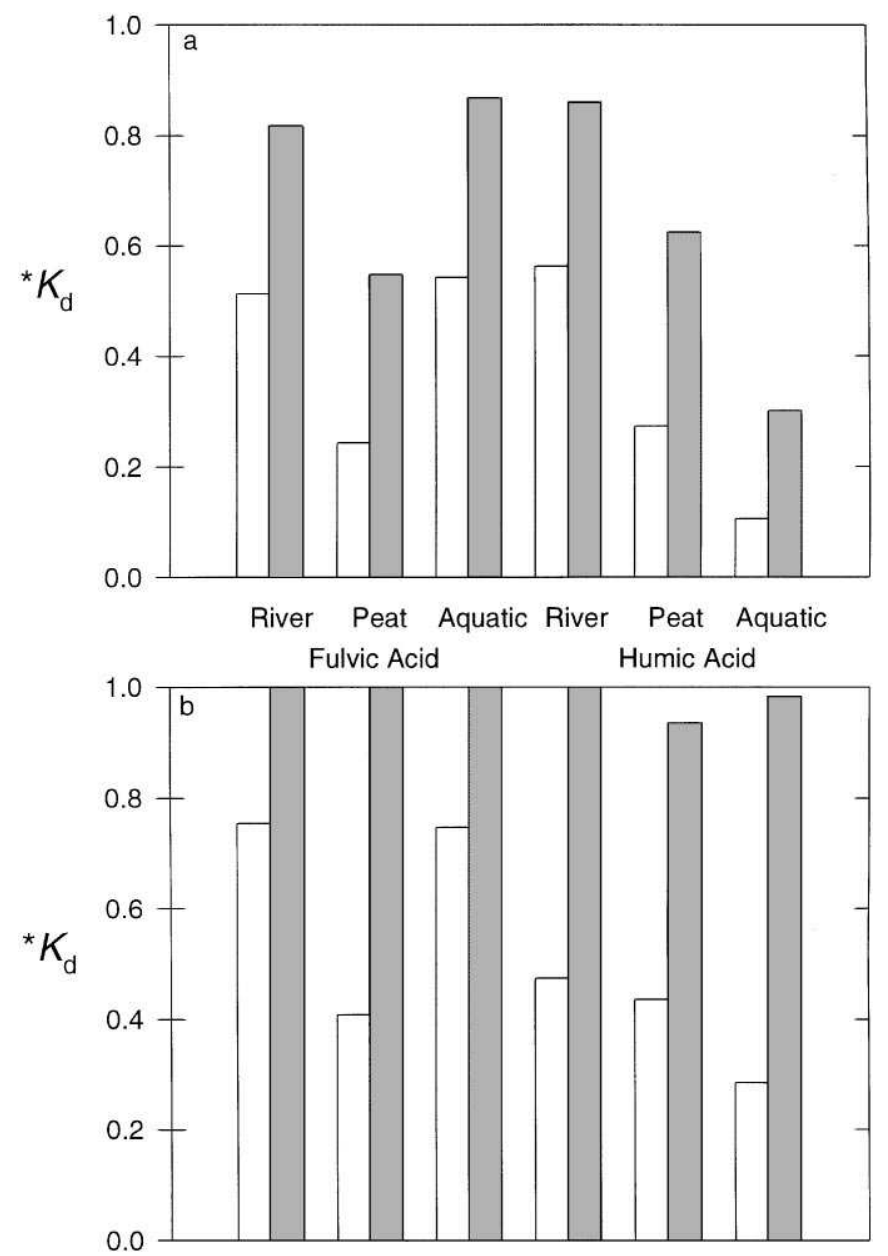

River Peat Aquatic River Peat Aquatic

Fulvic Acid

Humic Acid

Fig. 3. Value of $K_{\mathrm{d}}$ for the clay-humic complexes at the greatest addition of humic substance relative to that of the bare clay, ${ }^{*} K_{\mathrm{d}}$, for each of the humic substances at each of the initial concentrations of Cs (trace level and $10 \mu \mathrm{M}$ ) for (a) illite and (b) montmorillonite. White bars, trace Cs; Hatched bars, $10 \mu \mathrm{M} \mathrm{Cs}$.

substance couple. The trend mentioned above is more clearly demonstrated, namely a greater effect on illite than on montmorillonite and at trace levels of Cs. There is no clear trend linking the nature and origin of the humic substances and the reduction in Cs adsorption.

Fig. 4 shows the relative $K_{\mathrm{d}}$ value, ${ }^{*} K_{\mathrm{d}}$, for the highest HS loading as a function of $x_{\mathrm{HS}}$, the amount of HS calculated to be adsorbed (as described in Materials and Methods) for both clays at trace additions of Cs. About 10 times more humic substance is adsorbed on illite than on montmorillonite, with an average of 33 and 


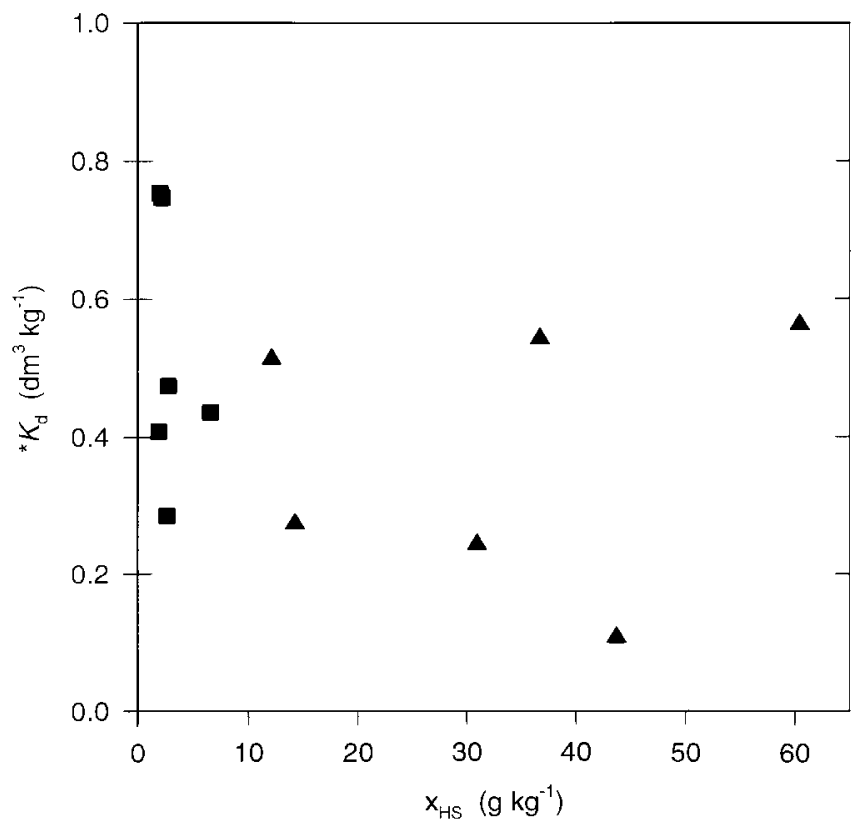

Fig. 4. Relative $K_{\mathrm{d}}$ value, ${ }^{*} K_{\mathrm{d}}$, (as explained for Fig. 3) for each clay-humic complex at trace levels of Cs as

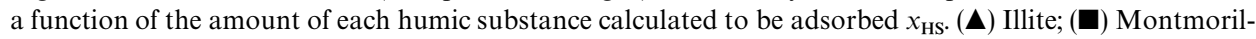
lonite.

$3 \mathrm{~g} \mathrm{~kg}^{-1}$, respectively. The average value of $* K_{\mathrm{d}}$ is lower for the illite complexes $(0.38 \pm 0.20)$ than that of the montmorillonite complexes $(0.53 \pm 0.13)$, but the difference is not significant. Fig. 5 relates the ratio of the relative $K_{d}$ value of each illite complex, ${ }^{*} K_{\mathrm{d}, \mathrm{I}}$, to that of montmorillonite, ${ }^{*} K_{\mathrm{d}, \mathrm{M}}$, at the maximum humic substance concentration and at trace levels of $C$ s to the relative amounts of humic substance adsorbed on each clay. There is a 10 -fold difference in the relative amount of HS adsorbed, $x_{\mathrm{HS}, \mathrm{I}} / x_{\mathrm{HS}, \mathrm{M}}$, and only a three-fold difference in the ratio of relative values of $K_{\mathrm{d}}$, denoted by $* K_{\mathrm{d}}$, on the two clays. There is no correlation between the two parameters, therefore the contrasting effect of humic substance on the affinity of the two clays for Cs is not simply a result of differing amounts of humic substance adsorbed.

\section{Discussion}

Preliminary studies (Staunton \& Roubaud, 1997) indicated that the presence of humic substance decreased the adsorption of caesium on mineral clays. The data presented in Figs. 1 and 2 confirm that this is a general phenomenon. Furthermore, the decrease induced by a given HS is generally enhanced as its concentration is increased. Were this effect observed for an actinide or a transition metal, the likely explanation would be that the solubility of the cation was increased by the formation of complexes in solution. This explanation is highly improbable for caesium, which 


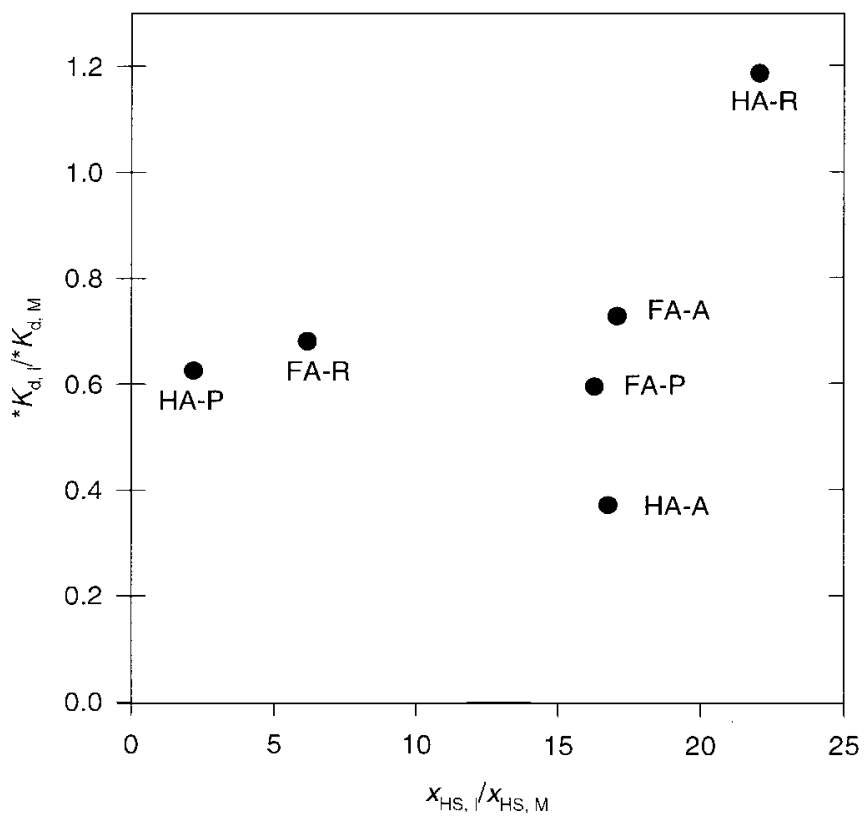

Fig. 5. Ratio of the relative $K_{\mathrm{d}}$ value for each illite complex denoted by $* K_{\mathrm{d}, \mathrm{I}}$, as presented in Fig. $3 \mathrm{a}$ to that of montmorillonite, ${ }^{*} K_{\mathrm{d}, \mathrm{M}}$ (Fig. $3 \mathrm{~b}$ ) at trace levels of Cs, as a function of the amount of each humic substance calculated to be adsorbed on illite, $x_{\mathrm{HS}, \mathrm{I}}$, relative to that adsorbed on montmorillonite, $x_{\mathrm{HS}, \mathrm{M}}$.

has a limited tendency to form complexes. There may be some association between caesium and the polyanion in solution because of the cation exchange capacity of the latter, which has, however, a preference for the divalent calcium, present at a much greater concentration $\left(0.33 \times 10^{-2} \mathrm{M}\right)$. In addition, the strong affinity of clay minerals for caesium would completely outweigh any tendency to complex formation in solution.

If it is accepted that the decrease in Cs adsorption is not due to complex formation in solution, it must result from a change in the affinity of the clay for caesium. Three hypotheses may be proposed to explain the change in affinity. First, a steric effect; access to cation adsorption sites, in particular the sites of greatest affinity for caesium, is impeded by the presence of the humic substance on the clay surface. Secondly, a decrease in the number of cation adsorption sites. Thirdly, a decrease in the average affinity of the cation adsorption sites for caesium. Each of these hypotheses will be considered in turn.

\subsection{Steric effect of adsorbed humic substances}

Some support for the hypothesis that the observed effect arises from steric hindrance comes from the relation between decreased adsorption and increase in humic substance added, and hence an increase in the amount adsorbed. However, only a small proportion of the humic substance is adsorbed because of the repulsion 
between the clay surface and the polyanion since both are negatively charged. There is no evidence of the adsorption of humic acids on internal sites of expanding clays such as montmorillonite. The coating of the clay surface by the humic substance is likely to be limited to positively charged edge sites caused by broken Al-OH groups. There is therefore no reason for the adsorption of humic substances on mineral surfaces to be related to the mineral CEC. Nor should adsorption depend on surface area, unless the same mineral with differing degrees of dispersion or grinding are compared. The positively charged edge sites are distinct from the electronegative frayed edge sites of illite (FES), with a very strong affinity for caesium, but they may be in close proximity. This proximity lends some support to the steric hindrance hypothesis. However, a steric effect should be related not only to the amount of humic substance adsorbed but also to its size. It is well-known that humic acids are larger than fulvic acids, although the difference may be less than was previously thought (Thurman, Wershaw, Malcolm \& Pinckney, 1982; Beckett, Jue \& Giddings, 1987). Therefore, if steric hindrance was an important factor in the reduction of Cs affinity, the effects of humic and fulvic acids should differ. No systematic difference was observed between the effect produced by humic acids and fulvic acids. In addition, although the decrease depended on the amount of HS adsorbed for a given substance, there is no correlation between $x_{\mathrm{HS}}$ and ${ }^{*} K_{\mathrm{d}}$ when all the data are considered. There is therefore no strong evidence to suggest that caesium adsorption is sterically hindered by the presence of humic substances on the clay surface.

\subsection{Decrease in number of adsorption sites}

Hsu and Chang (1995) have interpreted a reduction in caesium adsorption on clay in the presence of organic matter as a reduction in the number of adsorption sites. Such a phenomenon could not arise because of competition between cationic caesium and a polyanion. Organic matter, however, stabilizes clays aggregate formation, a greater number of clay platelets being associated (Vincente \& Robert, 1981; Gu \& Doner, 1992). Nevertheless, there is no evidence that this association leads to a decrease in the cation exchange capacity. Charge compensating cations on both internal and external adsorption sites remain exchangeable. Further, since aggregate formation involves planar surfaces more than clay edges, the strongly selective FES of illite should be less affected than the regular exchange sites, the latter playing an increasing role in caesium adsorption at higher caesium concentrations and on montmorillonite type clays. We observe the opposite; a greater effect on illite than on montmorillonite, particularly at trace additions of Cs. It therefore seems unlikely that the observed decrease in Cs adsorption is caused by a pro rata decrease in the number of adsorption sites, although a small decrease in the number of FES, with no consequence on the CEC could considerably affect the Cs affinity.

\subsection{Decrease in affinity for caesium}

Both the clay minerals studied adsorb caesium selectively. For example the Gaines-Thomas selectivity coefficients of the clays in the absence of humic substance 
and at trace levels of Cs are $7 \times 10^{8}$ and $4 \times 10^{3} \mathrm{M}^{-1}$ for illite and montmorillonite, respectively. As briefly outlined in the Introduction, the strong affinity of illite for trace amounts of caesium is usually attributed to the presence of highly selective frayed edge sites, which account for a tiny proportion (ca 1\%) of the cation exchange capacity. As the amount of caesium adsorbed increases, these FES become saturated and an increasing proportion of less highly selective sites participate in adsorption, leading to a decrease in the value of $K_{\mathrm{d}}$. If the decrease in Cs adsorption is due to a modification of the affinity of the clay surface when humic substances are present, then our observation that the effect is greater on illite at trace concentrations of Cs is important. This suggests that FES are influenced to a greater extent than are regular, planar exchange sites. Either humic substances are preferentially adsorbed on or near FES, or the affinity of the FES is changed more than that of the planar sites where adsorption occurs via $\mathrm{Ca}$ bridges. As stated above, the polyanion, like anions such as phosphate and sulphate, is likely to be adsorbed on positively charged edge sites arising from broken Al-OH groups (Stevenson, 1982). It is probable that the concentration of adsorbed humic substance is greater near the FES than on the planar surfaces. Unfortunately, the humic substances are too light to be observed directly by electron microscopy and so it is impossible to obtain direct evidence for this theory.

The presence of humic substance may also influence the affinity of the FES for caesium. This has been suggested by Hird, Rimmer and Livens $(1995,1996)$. The strong affinity of FES for caesium is thought to arise because Cs has a small hydration energy and so loses its hydration shell, forming a strong interaction with both clay platelets thereby closing the FES (Sawhney, 1972; Cornell, 1993). The presence of a macromolecule within, or at the outer edge of, the FES would impede or limit its collapse and so decrease its affinity for Cs.

The affinity of montmorillonite for Cs may be enhanced by the presence of trace impurities of illite. However, it is well known that the affinity of montmorillonite for the alkali metals increases in the order $\mathrm{Na}<\mathrm{K}<\mathrm{Rb}<\mathrm{Cs}$. This trend has been interpreted using the Hard and Soft Acid-Base Theory (Xu \& Harsh, 1990). It is therefore probable that anything that modifies the Misono softness parameter would influence selectivity. The free energy and the charge density of the clay surface are modified by the presence of the humic substance (Jouany, 1991). Indeed, since the clay systems studied were initially homo-ionic in calcium, the $K_{\mathrm{d}}$ is related to the selectivity coefficient, and hence to the thermodynamic exchange coefficient and the Gibb's free energy of the exchange reaction (Maes $\&$ Cremers, 1986). Some of the humic substance is adsorbed as bridging complexes via calcium on the exchange complex. It is probable that the selectivity of $\mathrm{Cs}-\mathrm{Ca}$ exchange differs from that of exchange between $\mathrm{Cs}$ and the $\mathrm{Ca}-\mathrm{HS}$ surface complex. This may also have some effect on the overall affinity of the surface for Cs. Overall the smaller effect on montmorillonite than on illite, and the smaller effect at larger concentrations of $\mathrm{Cs}$ for both clays, suggest that various mechanisms responsible for the decrease in affinity of planar sites are less important than those acting on the FES. 


\section{Conclusions}

Clay-humic substance complexes adsorb less caesium than do uncoated clays minerals. This decrease appears to be a general effect. For a given humic substance the effect increases with increasing humic substance adsorbed, although only a small proportion of the macromolecule is adsorbed by the clay. However, when all data are considered there is no correlation between the amount of humic substance on the clay and the decrease in Cs adsorption. No trend is observed for the nature (humic or fulvic acid) or origin (river, peat, aquatic) of the humic substances. A comparison of the relative effects on illite and montmorillonite at two concentrations of caesium leads to the conclusion that the phenomenon arises from a change in the affinity of the clay surface for caesium. Highly selective caesium adsorption sites, the frayed edge sites of illite, are particularly influenced. Although the adsorption of caesium in soils and geological formations, and hence its mobility and availability, is largely determined by clay content and mineralogy, the presence of organic matter may led to significant modifications.

\section{Acknowledgements}

This study received partial financial support from the Agence Nationale pour la Gestion des Déchets Radioactifs (ANDRA), France. Carbon analyses of the samples was carried out by the Laboratoire d'Analyse, Arras, INRA and characterisation of the humic substances supplied by the IHSS. The clay samples were gifts of D. Tessier, INRA, Versailles.

\section{References}

Barber, D. A. (1964). Influence of soil organic matter on the entry of ${ }^{137} \mathrm{Cs}$ into plants. Nature, 154, 1326-1327.

Beckett, R., Jue, Z., \& Giddings, J. C. (1987). Determination of molecular weight distributions of fulvic and humic acids using flow field-flow fractionation. Environmental Science and Technology, 21, 289-295.

Brouwer, E., Baeyens, E., Maes, B., \& Cremers, A. (1983). Cesium and rubidium ion equilibria in illite clay. Journal of Physical Chemistry, 87, 1213-1219.

Bunzl, K., \& Schultz, W. (1985). Distribution coefficients of ${ }^{137} \mathrm{Cs}$ and ${ }^{85} \mathrm{Sr}$ by mixtures of clay and humic material. Journal of Radioanalytical and Nuclear Chemistry, 90, 23-37.

Cornell, R. M. (1993). Adsorption of cesium on minerals: a review. Journal of Radioanalytical and Nuclear Chemistry, 171, 483-500.

Dumat, C., Cheshire, M. V., Fraser, A., Shand, C., \& Staunton, S. (1997). The effect of removal of soil organic matter and iron on the adsorption of radiocaesium. European Journal of Soil Science, 48, $675-683$.

Gu, B., \& Doner, H. E. (1992). The microstructure of dilute clay and humic acid suspensions revealed by freeze-fracture electron microscopy. Clays and Clay Minerals, 40, 246-250.

Hird, A. B., Rimmer, D. L., \& Livens, F. R. (1995). Total caesium-fixing potentials of acid organic soils. Journal of Environmental Radioactivity, 26, 103-118. 
Hird, A. B., Rimmer, D. L., \& Livens, F. R. (1996). Factors affecting the sorption and fixation of caesium in acid organic soil. European Journal of Soil Science, 47, 97-104.

Hsu, C. N., \& Chang, K. P. (1995). Study of factors dominating sorption and desorption of Cs in soil. Radiochimica Acta, 68, 129-133.

Jouany, C. (1991). Surface free energy components of clay-synthetic humic acid complexes from contactangle measurements. Clays and Clay Minerals, 39, 43-49.

Maes, A., \& Cremers, A. (1986). Highly selective ion-exchange in clay minerals and zeolithes. In: J. A. Davies, K. F. Hayes (Eds.), Geochemical processes at mineral surfaces, (pp. 254-295). Washington, DC: American Chemical Society.

Maguire, S., Pulford, I. D., Cook, G. T., \& Mackenzie, A. B. (1992). Caesium sorption-desorption in clay-humic acid systems. Journal of Soil Science, 43, 689-696.

OCDE (1987). Les incidences radiologiques de l'accident de Tchernobyl dans les pays de l'OCDE. OCDE: Paris.

Sawhey, B. L. (1972). Selective sorption and fixation of cations by clay minerals: a review. Clays and Clay Minerals, 20, 93-100.

Staunton, S., \& Roubaud, M. (1997). Adsorption of radiocaesium on montmorillonite and illite: Effect of charge compensating cation, ionic strength, concentration of potassium, caesium and fulvic acid. Clays and Clay Minerals, 45, 251-260.

Stevenson, F. J. (1982). Clay-organic complexes and formation of stable aggregates. In: Humus chemistry, (pp. 374-400). New York: Wiley-Interscience.

Theng, B. K. G., \& Scharpenseel, H. W. (1975). The adsorption of ${ }^{14} \mathrm{C}$-labelled humic acid by montmorillonite. Proceedings of the International Clay Conference, IL USA (pp. 643-653).

Thurman, E. M., Wershaw, R. L., Malcolm, R. L., and Pinckney, D. J. (1982). Molecular size of aquatic humic substances. Organic Geochemistry, 4, 27-35.

Van Bergeijk, K. E., Noordijk, H., Lembrechts, J., \& Frissel, M. J. (1992). Influence of pH, soil type and soil organic matter content in soil-to-plant transfer of radiocesium and strontium as analyzed by a non parametric method. Journal of Environmental Radioactivity, 15, 265-276.

Vicente, M. A., \& Robert, M. (1981). Rôle des acides fulviques et humiques dans la microagrégation des particules argileuses. Comptes Rendus de l'Académie des Sciences de Paris, 292, 1161-1166.

Xu, S., \& Harsh, J. B. (1990). Hard and soft acid-base model verified for monovalent cations selectivity. Soil Science Society of America Journal, 54, 1596-1601. 